\title{
Integrated engineering environment for the process FEED of offshore oil and gas production plants
}

\author{
Ji-Hyun Hwang ${ }^{1}$, Myung-II Roh*2 and Kyu-Yeul Lee ${ }^{3}$ \\ ${ }^{1}$ Department of Naval Architecture and Ocean Engineering, Seoul National University, Shinlim-Dong, \\ Seoul, 151-742, Korea \\ ${ }^{2}$ School of Naval Architecture and Ocean Engineering, University of Ulsan, Mugeo-Dong, Nam-gu, Ulsan, \\ 680-749, Korea \\ ${ }^{3}$ Department of Naval Architecture and Ocean Engineering, Research Institute of Marine Systems Engi- \\ neering, Seoul National University, Shinlim-Dong, Seoul, 151-742, Korea, \\ (Received December 22, 2011, Revised March 5, 2012, Accepted March 7, 2012)
}

\begin{abstract}
In this paper, an offshore process front end engineering design (FEED) method is systematically introduced and reviewed to enable efficient offshore oil and gas production plant engineering. An integrated process engineering environment is also presented for the topside systems of a liquefied natural gas floating production, storage, and offloading (LNG FPSO) unit, based on the concepts and procedures for the process FEED of general offshore production plants. Various activities of the general process FEED scheme are first summarized, and then the offshore process FEED method, which is applicable to all types of offshore oil and gas production plants, is presented. The integrated process engineering environment is presented according to the aforementioned FEED method. Finally, the offshore process FEED method is applied to the topside systems of an LNG FPSO in order to verify the validity and applicability of the FEED method.
\end{abstract}

Keywords: offshore process FEED; integrated process engineering environment; topside systems; offshore oil and gas production plants; LNG FPSO; offshore projects

\section{Introduction}

\subsection{Offshore production plants}

As the demands for oil and gas, representative offshore resources, are increasing relative to those of other energy resources, potential offshore fields are being explored. The installation area for offshore production plants is gradually moving toward the deep sea, and the need for multifunctional offshore plants is increasing (Jung et al. 2006). As such, the demand for floating production, storage, and offloading (FPSO) units, which can produce, store, and offload crude oil and gas in the deep sea, is also increasing. In particular, the demand for liquefied natural gas (LNG) FPSO projects will grow along with the increased demand for natural gas. Consequently, the midand long-term prospects for offshore production plants are quite promising (International Maritime Associates 2010).

*Corresponding author, Professor, E-mail: miroh@ulsan.ac.kr 
Oil and gas FPSO units are production plants used to transfer offshore oil and gas to onshore plants. The job of a production plant is to separate the well stream into three components (typically called 'phases'): oil, gas, and water. The plants then process these phases into marketable products or dispose of them in an environmentally acceptable manner. In mechanical devices called 'separators,' gases are removed from the liquids and 'free water' is separated from the oil. These steps remove a sufficient amount of light hydrocarbons to produce stable crude oil with a volatility level (vapor pressure) that meets sales criteria. The gas that is separated must be compressed and treated for sales. The separated gas is usually saturated with water vapor and must be dehydrated to an acceptable level. In some geographical locations, it may be necessary to remove the heavier hydrocarbons to reduce the hydrocarbon dew point. Contaminants such as $\mathrm{H}_{2} \mathrm{~S}$ and $\mathrm{CO}_{2}$ may be present at levels higher than those acceptable to the gas purchaser and must therefore be removed.

\subsection{Offshore LNG FPSO}

\subsubsection{System description}

An example of an LNG FPSO is shown in Fig. 1. The plant is divided into three parts: a fieldspecific part, a liquefaction part, and a utility part. The field-specific part separates the natural gas from the condensate and stabilizes the condensate. The process design and equipment for the fieldspecific part vary according to the conditions of the gas field. The liquefaction part treats the natural gas in accordance with the requirements of the liquefaction plant. The goal of the treatment procedure is to separate heavier hydrocarbons (LPG) and convert the natural gas to LNG products. The utility part of the plant provides power, cooling water, nitrogen, and other necessary materials to the required specific and generic equipment.

The well stream is introduced into the LNG liquefaction plant through a riser/swivel or internal/

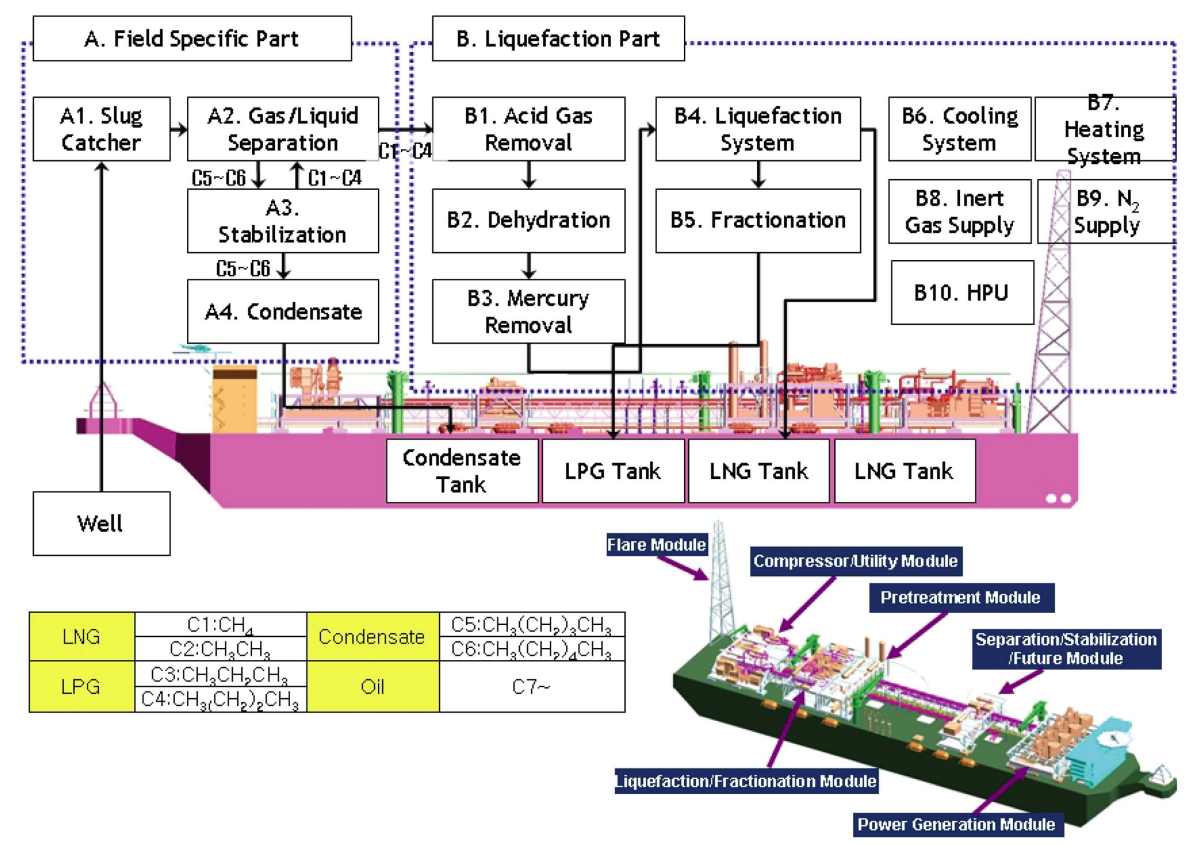

Fig. 1 Schematic diagram of an offshore LNG FPSO 
external turret connected to the gas field. The introduced gas and condensate mixtures first pass into the slug catcher, where the slug flow is converted into a stabilized gas/condensate flow. An initial separation of the gas and condensate is conducted to improve the separation efficiency of the next gas/liquid separator. Bulk separation of the gas and condensate takes place in the gas/liquid separator. The separated condensate flows to the stabilization column where it undergoes treatment to meet the specifications for stable storage and transportation. Lighter hydrocarbons (methane, ethane, propane, and butane) are isolated in the stabilization column and returned to the gas process after compression. The separated natural gas is further treated in the cooler/heater, after which it flows to the liquefaction part.

The treated natural gas enters the acid gas removal column (the so-called 'amine tower') for carbon dioxide $\left(\mathrm{CO}_{2}\right)$ removal. Carbon dioxide can form hydrates and hydrogen sulfide $\left(\mathrm{H}_{2} \mathrm{~S}\right)$, which is corrosive to materials and toxic to humans. Since $\mathrm{CO}_{2}$ poses a risk for hydrate formation at concentrations greater than $100 \sim 150$ ppmv, the target design concentration of $\mathrm{CO}_{2}$ is less than 50 ppmv. As even a small amount of $\mathrm{H}_{2} \mathrm{~S}$ poses severe problems; therefore, the target design concentration of $\mathrm{H}_{2} \mathrm{~S}$ is less than $2 \sim 4$ ppmv. The absorber and regeneration column are designed to maintain the removal efficiency regardless of the ship's motion or the marine environment.

The next step involves dehydration and mercury removal column (the so-called 'absorber column') to respectively remove water, which may form ice, and mercury, which can damage equipment and pipes during the cryogenic process. The water and mercury contents in the gas will be reduced to less than $1 \mathrm{ppm}$ and $0.05 \mathrm{~g} / \mathrm{Nm} 3$, respectively. Water is removed through solid bed desiccants containing molecular sieve material, a proven technology that is compatible with offshore operations. Heat for the regeneration of solid bed desiccants is provided by a heat recovery steam generator or a heating system.

Natural gas treated to meet the requirements of the liquefaction plant is next transferred to the liquefaction system. The liquefaction system is divided into two parts: a heat exchanger used to convert natural gas to liquefied natural gas and compression and expansion cycle refrigerants to reduce the refrigeration temperature below $-163^{\circ} \mathrm{C}$. Natural gas is passed through a heat exchanger for precooling, liquefaction, and sub-cooling. Nitrogen is extracted in an independent nitrogen removal column or in a flashing device, while the liquefied natural gas flows to the storage tank. Heavier hydrocarbons (natural gas liquid) are removed after precooling in order to meet the specifications for sale. The heavier hydrocarbons flow to the fractionation column and are separated along with light hydrocarbons and liquefied petroleum gas (LPG). The separated light hydrocarbons are then returned to the natural gas stream.

\subsubsection{Offshore considerations}

An offshore plant must be compact, lightweight, and be designed with a high level of inherent process safety because of the limited deck area. Another requirement to consider is stable and robust operation in a marine environment, taking into account vessel motion. The offshore plant must offer a high degree of modularity, ease of operation, a low equipment count, quick start-up, and high availability. In addition, the plant must be able to operate under a variety of process conditions and possess a high degree of inherent process robustness because there is a possibility that it will have to treat natural gas or associated gases collected from various gas fields.

In order to develop and construct an offshore generic LNG liquefaction plant, a few technical matters must first be considered. The main pieces of equipment, such as a compressor, expander, gas turbine, column, heat exchanger, and separator, have been developed to be installed on floating 
facilities. Much research and numerous feasibility studies have been conducted to minimize the effects of possible liquid misdistribution in each column and spiral type heat exchanger due to ship motion.

Other technical matters to consider are LNG storage and offloading. The transportation of LNG is aptly handled by the LNG carrier. However, it is possible that the cargo tank of the floating LNG will be partially filled during liquefaction operations. This may result in sloshing due to ship motion and consequent damage to the cargo tank. Design factors to minimize the loss of containment and the effect of sloshing must be carefully studied when considering hull fabrication. Offloading is not considered to be an important technical challenge in a benign environment. However, offloading is universally recognized as a serious technical barrier for LNG FPSOs. Feasibility studies have been conducted to establish offshore LNG transfer techniques and appropriate methods associated with side-by-side offloading; tandem offloading and flexible loading arms may be suggested in the near future.

\subsubsection{Applicable offshore $L N G$ refrigeration processes}

The refrigeration system plays a key role in an LNG liquefaction plant, and the refrigeration system typically accounts for $30 \%$ to $40 \%$ of the overall capital cost of a LNG liquefaction plant. The basic principle behind the cooling and liquefaction of natural gas is the Joule-Thomson effect, according to which the refrigerant temperature decreases when it is allowed to expand freely through a Joule-Thomson valve or expander after compression. Regarding heat transfer between the natural gas and the refrigerant, the refrigeration system is appropriately designed to match the cooling/heating flux in composite curves. These principles apply to all liquefaction processes, and several licensed processes are used to increase the thermal efficiency and the unit capacity.

The LNG industry has a history longer than 40 years, beginning with the permanent operations of the Camel plant in Algeria in 1964 (Barclay and Yang 2006). The earliest plants utilized singlecycle processes based on cascaded refrigeration or single mixed refrigerant (SMR) methods with train capacities less than one million tons per annum (MTPA). These were quickly replaced by the two-cycle propane pre-cooled mixed refrigerant (C3MR) process developed by Air Products and Chemicals Inc. (APCI). This process became the dominant liquefaction process technology by the late 1970 s and is still competitive in many cases.

The economics of scale, improved process simulation tools, and better equipment (liquid expander and gas turbine driver) have improved performance and increased the capacity of liquefaction trains. Recently, three-cycle processes such as the AP-XTM and Conoco Phillips Optimized Cascade techniques have been selected for new projects. The three-cycle AP-XTM process allows onshore train capacities to be increased to approximately $7.5 \sim 10$ MTPA and have thus overcome the typical process bottlenecks such as the main cryogenic heat exchanger diameter and the propane refrigerant compressor capacity. Various refrigeration systems with their respective heat transfer mechanisms are shown in Fig. 2.

In contrast to the onshore liquefaction process, offshore applications involve distinctly different process requirements according to the train capacity. In the case of small-scale applications (below 2 MTPA), high-efficiency C3MR cycles that are preferable for onshore LNG plants will not meet the future needs of offshore liquefaction projects because, for example, the equipment count is high and the needs for refrigerant storage are higher. For an offshore LNG liquefaction system, one must consider safety and simplicity more than thermal efficiency and unit capacity. These requirements are especially important for small-scale offshore LNG liquefaction plants. There are a few 


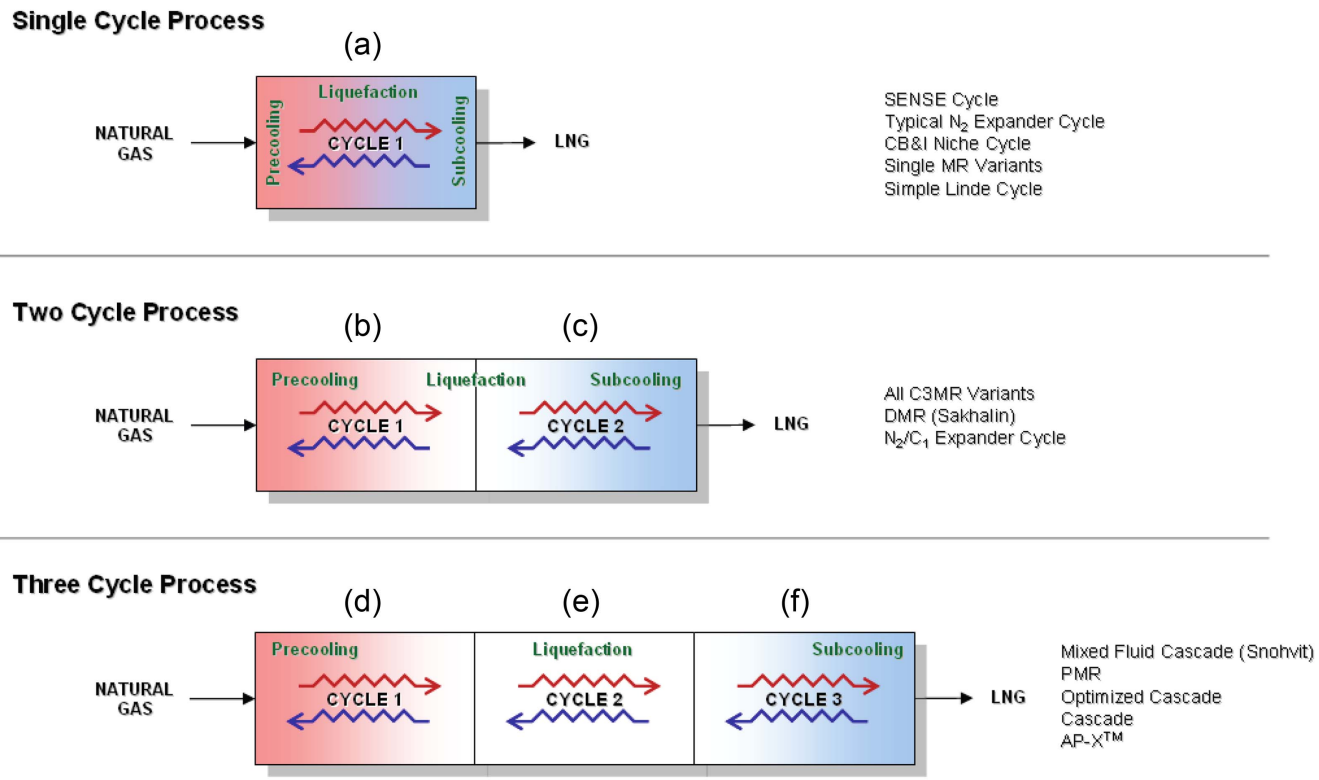

Fig. 2 Various refrigeration systems and their respective heat transfer mechanisms

techniques such as expander and single mixed refrigerant processes that are suitable for use in a small-scale offshore LNG liquefaction plant. However, in the case of medium-sized (2.5 4 MTPA) plants, mixed refrigerant cycles are still adopted due to their higher thermal efficiencies and the limited space in offshore operations. For example, dual mixed refrigerant (DMR) cycles have been applied in two major offshore LNG projects: SHELL LNG FPSO and Petrobras LNG FPSO.

\subsection{Related works}

The engineering of offshore production plants is divided into two phases: the front-end engineering design (FEED) phase and the detailed engineering phase. Of these two phases, the FEED phase is more critical for determining the feasibility of specific well area development. An economic analysis on the development of a specific well area is performed based on the outputs of the FEED phase. Based on the results of this analysis, the detailed engineering phase is executed if the value of the development is sufficiently large. In other words, the FEED phase, which is the basis of the detailed engineering phase and of the feasibility of development on specific well areas, is the most important overall offshore plant phase in determining project success. The final outputs of the FEED phase are the total costs, the weight, and the layout of an offshore plant. The feasibility of offshore plant projects is determined by these final outputs. The system capacity and size of each topside system are first determined so as to ascertain such final outputs as the total cost, weight, and layout. Offshore process engineering, one of the highest priority areas in engineering, is the most important component in calculating the system capacities and sizes of topside systems. The overall engineering for offshore topside systems includes the offshore process, piping, mechanical engineering, instrumentation, electrical engineering, and outfitting engineering. Major engineering data are derived through offshore process engineering in order to obtain the final FEED outputs. As such, an effective method for performing offshore process engineering is needed 
to increase efficiency.

While many offshore projects such as drillships, semi-submersible rigs, fixed platforms, and FPSOs have been constructed, Korean shipyards have concentrated more on the construction and installation than to the engineering in the early stage of these offshore projects. In the case of process engineering, Korean shipyards only have to perform the construction and installation according to process engineering results obtained from sub-engineering contractors such as Technip (2012), Mustang Engineering (2012), Doris Engineering (2012) etc. For example, Technip was involved in major offshore FPSO projects such as Petrobras P-37, Elf Nkossa, Total Dalia, and Total Akpo, while Mustang Engineering performed major offshore FPSO projects including Chevron Agbami and Nexus Crux. Doris Engineering carried out CPTL Farwah FPSO projects.

While process engineering technology is partially understood by Korean shipyard workers due to technical meetings between Korean shipyard representatives and sub-engineering contractors during the construction stage of offshore projects, process engineering is still regarded as an exclusive technology of the top offshore engineering companies. Fortunately, a process engineering method with extreme limitations was introduced in recent offshore conferences and papers. However, universities and research centers in Korea are not conducting process engineering studies of offshore plants, but rather research is performed in fields related to structural mechanics and fluid dynamics, such as the motion and hydroelastic responses of offshore structures (Shin et al. 2000, Lee et al. 2000), the reliability of fatigue and strength analyses of offshore structures (Lee et al. 1998, Kim et al. 2004), and the mooring systems of offshore structures (Na et al. 2004, Kim et al. 2006).

In overseas countries, specialized offshore engineering companies such as Technip, Mustang Engineering, and Doris Engineering are accumulating experience in process engineering through their involvement in several oil and gas development business consortiums. However, universities and research centers in foreign countries are performing basic research related to structural and fluid dynamics, not actual studies related to the process engineering of offshore plants (Lake et al. 2000, Newman and Lee 2002, Matsuura and Bernitsas 2006).

\section{The concept of offshore process FEED engineering}

\subsection{Offshore and onshore engineering}

Shown in Fig. 3 is the offshore and onshore engineering scheme for refining petroleum products from oil and gas. As mentioned above, the main function of offshore engineering is to separate light hydrocarbon components from heavy hydrocarbon components, refine each hydrocarbon component to meet the specifications for saleable oil and gas, and transfer the oil and gas products to onshore plants. The main function of onshore engineering is to convert the oil and gas into petroleum products. Onshore engineering consists of two fields; one involves the refining of heavy hydrocarbon oil products through distillation and fractionation processes, and the other pertains to light hydrocarbon gas products through refrigeration processes. In the case of LNG FPSO, a liquefaction process, which is a part of the onshore engineering field, is applied to the offshore engineering field. As such, engineering technologies have gradually moved from onshore to offshore, and great expansion of the offshore engineering field is expected in the future. 


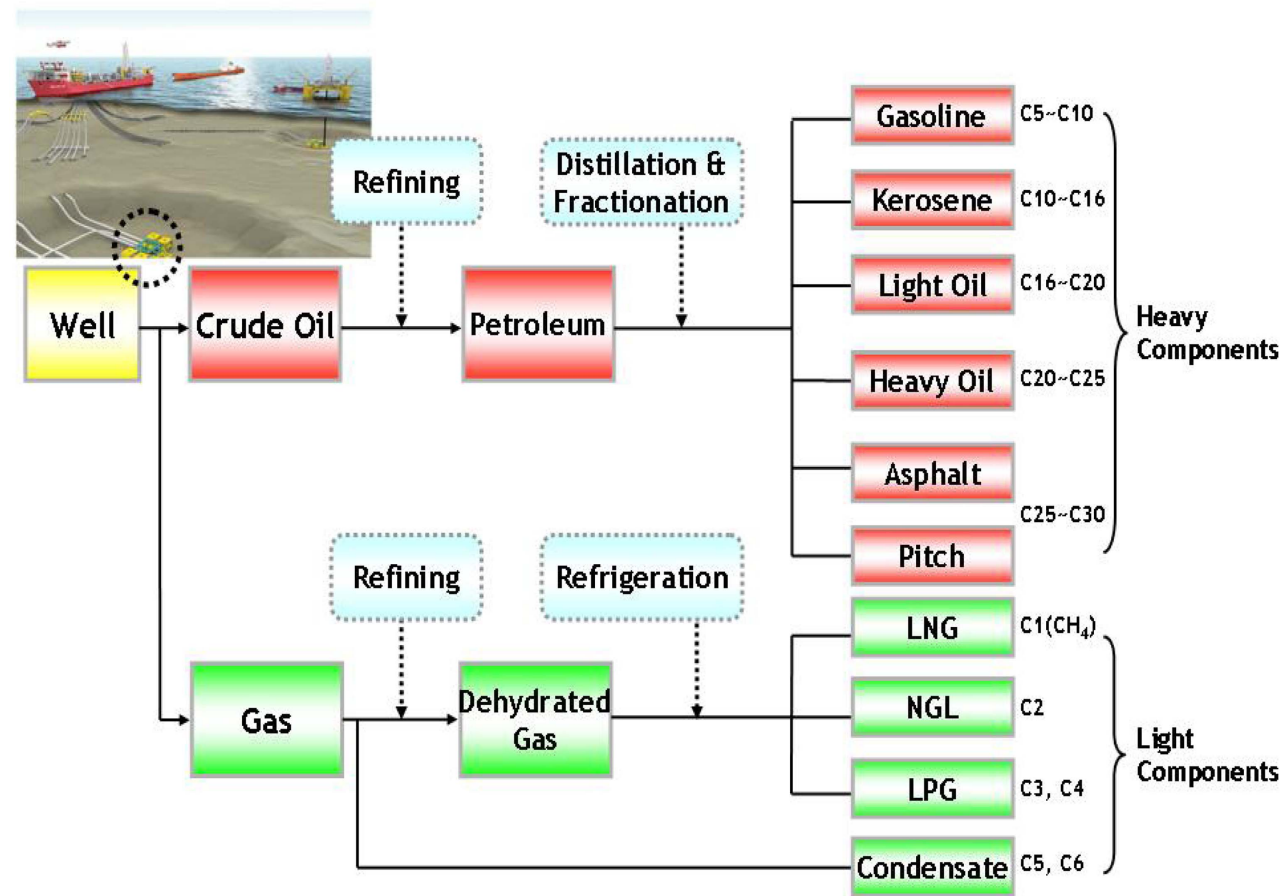

Fig. 3 Productions of oil and gas in offshore and onshore engineering

\subsection{Offshore process FEED engineering}

Offshore plants consist of two main systems: a topside system and a hull system. Topside systems, which are those that take place on the decks of offshore plants, are used for the production of oil and gas. Hull systems, which are located on the lower decks of offshore plants, are used for the storage of oil and gas. The importance of topside systems is far greater than that of hull systems when considering the main function of an FPSO. Fields of engineering related to topside systems include offshore process engineering, piping engineering, mechanical engineering, instrumentation engineering, electrical engineering, and outfitting engineering. Among these, offshore process engineering comprises the majority of topside system engineering (Hwang et al. 2008).

Offshore process engineering consists of the FEED and detailed engineering. The specifications of process and utility systems, which are located on the topsides parts of plants, are determined according to client specifications, rules, and regulations. The determined specifications are thoroughly examined and actualized in the detailed engineering stage. That is, the duration of detailed engineering can fluctuate according to the results of FEED. Offshore plant projects can actually be canceled because of the FEED results. As such, offshore process FEED is an engineering phase of great consequence because it can determine whether or not an offshore plant can be constructed.

\subsubsection{The definition of offshore process FEED activities}

Offshore process FEED activities are shown in Fig. 4. FEED results estimate the overall costs, weights, and layouts of offshore plants. The process FEED activities that yield the FEED results are as 


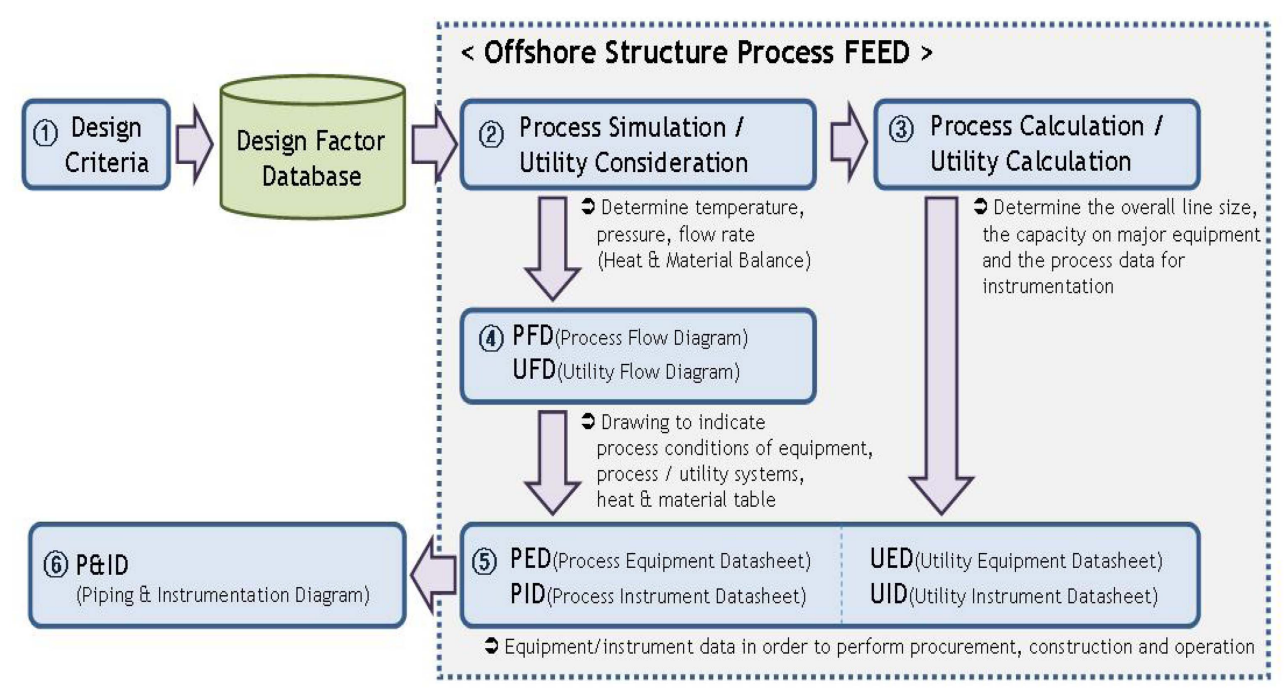

Fig. 4 Offshore process FEED activities

follows. Design criteria, such as the engineering considerations of equipment, instruments, and pipes on topside systems, are first determined after establishing the customer requirements (Fig. 2(a)). Next, the overall process flow, which corresponds to the production flows of oil and gas, and the utility flow, which supports the process flow, are defined and simulated to calculate physical and thermodynamic properties, as well as the utility specifications for each process and utility system (Fig. 2(b)). The specifications of the equipment, instruments, and pipes are then determined based on the results of a process simulation and utility considerations (Fig. 2(c)). A process flow diagram (PFD) and utility flow diagram (UFD), which represent the heat/material table and the overall safety and control logic, are also prepared based on the results of a process simulation and utility considerations (Fig. 2(d)). Next, a process equipment datasheet (PED), process instrument datasheet (PID), utility equipment datasheet (UED), and utility instrument datasheet (UID) are generated in order to obtain information on the equipment and instruments (Fig. 2(e)). Finally, a piping \& instrumentation diagram (P\&ID), which shows the safety, operation, and maintenance factors of each system and vendor data for the equipment and instruments, are preliminarily prepared based on the PFD and UFD (Fig. 2(f)). The aim of the above mentioned process activities is to obtain the overall costs, weights, and layouts of offshore plants in order to determine the feasibility of well developments in specific locations. If economic feasibility is established based on the FEED results, detailed process engineering is performed.

\subsubsection{Purpose of process FEED}

The first goal in performing process FEED is to determine the sizes of the equipment and instruments which are the main components of topside systems. This is achieved by calculating the overall capacities of a topside system and receiving suitable information from specific vendors. The second aim is to calculate the sizes of the pipes which connect the components of topside systems through process simulation and utility considerations. By calculating the sizes of the equipment, instruments, and pipes, the overall layout of a topside system can be efficiently determined. The various cranes which are necessary to construct and install topside systems and pipes can also be 
selected through an examination of weight information. Most importantly, the total cost of a topside system and its pipes can be estimated. Therefore, process FEED results are the most important factors when performing the overall engineering, construction, and installation of an offshore plant and can ultimately affect the success or failure of an offshore project.

\section{The offshore process FEED method}

The overall schematic of the offshore process FEED method can be shown in Fig. 5. Through this type of FEED method, the capacities and sizes of topside systems and pipes can be efficiently determined without unnecessary time-consuming engineering work. Engineering data from vendors can be received based on the overall capacity and size of a topside system. In the long run, the potential feasibility of specific well development can be rapidly determined because the total costs, weights, and effective layout of an offshore plant topside system can be obtained via the offshore process FEED method.

\subsection{Thermodynamic methods study}

In physics and thermodynamics, an equation of state is a relationship between state variables (A to $\mathrm{Z}$ of Thermodynamics 1998). More specifically, an equation of state is a thermodynamic equation describing the state of matter under a given set of physical conditions. It is a constitutive equation that provides a mathematical relationship between two or more state functions associated with

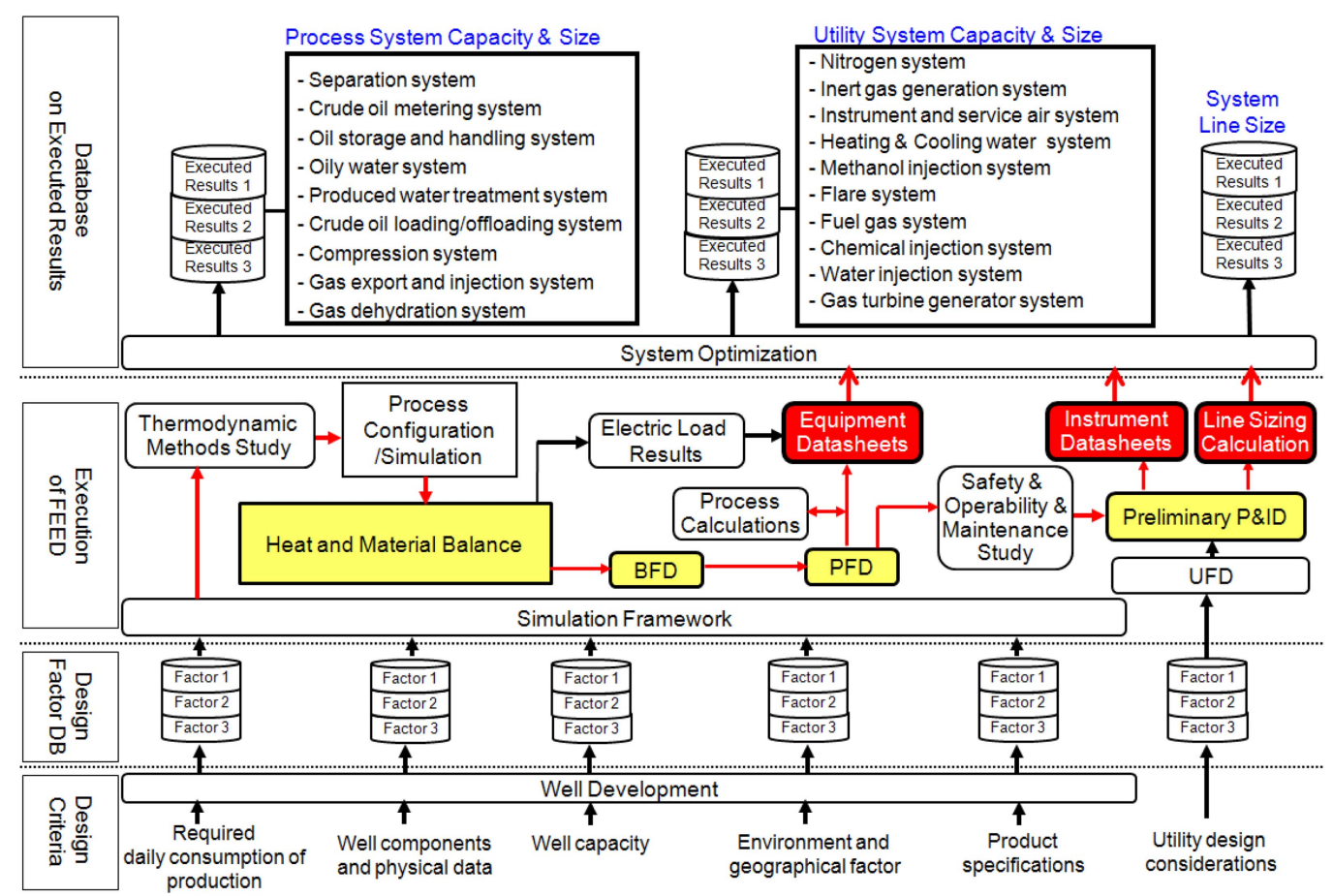

Fig. 5 Schematic of the offshore process FEED engineering method 
matter, such as its temperature, pressure, volume, or internal energy. Equations of state are useful in describing the properties of fluids, mixtures of fluids, solids, and even the interior of stars. The Peng-Robinson equation is widely used as a mathematical model to calculate fluid phase equilibrium. The Peng-Robinson equation was developed in 1976 in order to satisfy the following goals.

$$
\begin{aligned}
& P=\frac{R T}{V_{m}-b}-\frac{a_{c} \cdot\left[1+m\left(1-\left(T / T_{c}\right)^{0.5}\right)\right]^{2}}{V_{m}\left(V_{m}+b\right)+b\left(V_{m}-b\right)} \\
& a_{c}=0.45724 \frac{R^{2} T_{c}^{2.5}}{P_{c}}, b=0.07780 \frac{R \cdot T_{c}}{P_{c}} \\
& m=0.37464+1.54226 \omega-0.26992 \omega^{2}
\end{aligned}
$$

First, the parameters should be expressible in terms of the critical properties and the acentric factor. Second, the model should provide reasonable accuracy near the critical point, particularly for calculations of the compressibility factor and liquid density. Third, the mixing rules should not employ more than a single binary interaction parameter, which should be independent of the temperature, pressure, and composition. Finally, the equation should be applicable to the calculations of all fluid properties in the natural gas processes. For the most part, the Peng-Robinson equation exhibits performance similar to that of the Soave equation, although it is generally superior in predicting the liquid densities of many materials, especially nonpolar substances.

\subsection{Process and utility configuration/simulation study}

The purpose of performing the process and utility configuration and the simulation using the above mentioned thermodynamic methods is to calculate the physical properties for each stream based on a unit operation at the operating conditions.

Case studies are performed according to major considerations such as the temperature, pressure, flow rate, and mole fraction from well reservoirs, as well as the efficient configuration of main topside systems. The case that satisfies the most severe condition for each system is then considered as the design case. The simulation study and configuration comprise the most important stage when determining the specifications of equipment, instruments, and piping in offshore process FEED engineering. Therefore, optimized methods pertaining to the simulation and configuration study should be developed to determine the optimal operating conditions and configurations. This will in turn lead to successful FEED results in offshore production projects.

\subsection{Heat and material balance}

Heat and material balance is the process of calculating the physical properties and electric loads of each topsides process system through process simulation and configuration. The heat and material balance provides the most important data in topsides process system engineering. The specifications of equipment, instruments, and pipes for the topsides process systems are determined based on the heat and material balance. Therefore, the heat and material balance should be exactly and rapidly determined in order to produce successful FEED results in the early stage. Thus, process data 
should be rapidly and efficiently calculated and managed in the early FEED stage. This is critical when performing FEED engineering in oil and gas production plants.

\subsection{Block flow diagram (BFD)}

A BFD is a drawing that shows the overall flow in a topside system. Organic relationships among the oil processing systems, gas processing systems, and water processing systems can be illustrated through a BFD. All engineers involved in a project can use the BFD to understand a topside system in a specific oil and gas production plant.

\subsection{Process flow diagram (PFD)}

A PFD is a drawing that shows the safety and control logic of a topsides process system, as well as the heat and material tables which present the engineering data (temperature, pressure, flow rate, and mole fraction) for each topsides process system for a specific design case. Engineering information on all process equipment from a specific vendor can be obtained based on the PFD. The PFD is expanded to a P\&ID by incorporating the safety, operation, and maintenance factors of all topsides process systems. To be more specific, a PFD is a schematic drawing of a process or utility unit that shows all relevant physical and other process data, the main utility characteristics, the basic process control elements, and the main dimensions of the process equipment. A PFD should contain a list of included equipment items identified by tag numbers in the drawing title block. A process or utility engineer is responsible for the preparation of PFDs, and no modifications to a PFD should be made without the engineer's authorization. If a design provides for different modes of operation, such as different crudes, feedstocks, or cut points, a distinction should be made through the use of letters, e.g., mode of operation A, B, etc. For more complicated cases, separate PFDs should be prepared for each mode of operation. PFDs provided by process licensors or other third parties should be redrawn with symbols and identifications in accordance with specific rules and regulations. PFDs for pressure relief systems should indicate the relief quantities, physical characteristics, and conditions for each relief valve and depressurization valve for each individual and general emergency case.

\subsection{Utility balance}

Utility systems play an important role in supporting process systems. Engineering data for each topsides utility system are determined after fixing the engineering conditions of each process system. Utility balance is the process of calculating the physical properties and electric loads of each topsides utility system through utility considerations. The utility balance is the most important factor in topsides utility system engineering. The specifications of equipment, instruments, and pipes of topsides utility systems are determined based on the utility balance. Therefore, utility balance should be exactly and rapidly determined after fixing the process concepts and process data.

\subsection{Utility flow diagram (UFD)}

A UFD is a drawing that shows the safety and control logic of a topsides utility system, as well as the utility balance tables, which present engineering data (temperature, pressure, flow rate, and 
mole fraction) for each topsides utility system after all utility systems such as the instrument air, utility air, seawater, freshwater, cooling water, diesel oil, and lube oil have been diagrammed. Engineering information on all utility equipment from a specific vendor can be obtained based on the UFD. The UFD is expanded to a P\&ID by incorporating the safety, operation, and maintenance factors for all topsides utility systems.

\subsection{Process and utility calculations}

Process calculation is the optimized engineering of equipment, piping and instruments of a topside system based on the results of process configuration/simulation. Normally, specific references from the API, ASME, NACE, ISO, NFPA, etc. can be used when process and utility calculations are performed. The following calculations should be considered. First, design parameters such as the design pressure, temperature, and design factors should be calculated according to specific rules and regulations. Next, equipment design of vessels, heat exchangers, equipment nozzles, lever controls, and material and corrosion allowance should be considered. Third, the piping design has to be considered, including the materials and corrosion allowance, insulation and tracing, minimum pipe size, and line sizing. Fourth, flare and vent design should be performed according to specific rules and regulations. Finally, other specific systems pertaining to the drain, instrument air, sea and cooling water, steam generation, fuel gas, glycol dehydration, and chemical injection should be considered as special activities in process and utility calculations.

\subsection{Equipment datasheets}

Datasheets for the equipment in a topside system are prepared on the basis of process configuration/simulation and process calculations. Process datasheets that contain only equipment process data should be prepared first so that they can be sent to specific equipment vendors. Several equipment vendors should then be considered in potential vendor lists. Finally, one vendor of specific equipment should be selected as the contractor after technical evaluations have been performed. Detailed equipment data from the selected vendor can then be received, and equipment datasheets can be finalized. Therefore, all necessary data for the procurement, installation, and operation of equipment are contained in the equipment datasheets.

\subsection{Safety/operability/maintenance study}

Safety and operability studies of topside systems (e.g., hazard operability studies) are performed on the basis of the engineering data from the PFD and UFD in order to consider all potential hazardous factors in topsides process engineering. A maintenance study on the equipment and instruments of a topside system is then performed so that the lifetime requirements of the systems can be met. A piping and instrumentation diagram (P\&ID) can subsequently be developed according to the results of safety, operability, and maintenance studies.

\subsection{Preliminary piping and instrumentation diagram (P\&ID)}

The PFD and UFD can be expanded to P\&IDs for each topside system after incorporating the results of safety, operability, and maintenance studies and after receiving the vendor data. The P\&ID 
shows all data, such as the operating conditions, process control and safety logic, etc. for all equipment, instruments, and pipes. To be more specific, a P\&ID is a pictorial representation of a process or utility unit that shows all of the equipment, including installed spares and the associated piping and piping components, instrumentation, heat tracing, and insulation. An elevated view is normally shown, although tank farms are usually shown in plane view. All piping and piping components should be shown with their size, piping class, and tag number. Equipment, piping, and instrument numbering should logically follow the process flow and preferably be drawn from left to right and from top to bottom on vertical equipment, except for column trays. The schematics should show the specific engineering requirements necessary for the design, e.g., sloping lines, minimum straight pipe lengths, equipment elevations, no pockets, enter at top of line, minimum or maximum distances, etc. These requirements must be stated in words (or with a symbol), as a P\&ID is not an isometric representation. Process conditions and physical data should not be shown on the P\&ID. The column above the title block of a P\&ID should be reserved for the following:

- Reference to the legends sheet accompanying the P\&ID

- Notes indicating that the P\&ID should start from the top of the page and be numbered from 1. If a note is deleted, the number should not be used for another note but should instead be shown as 'deleted.' Notes should cover non-standard instructions

- List of equipment shown on the P\&ID

- Register of revisions and P\&ID issues.

A separate P\&ID should be prepared for each utility system, e.g., those for cooling water, steam (high, medium, and low pressure), condensate, air, water, etc. Combining several systems on one P\&ID is subject to the approval of the Principal. P\&IDs are prepared under the supervision of process or utility engineers in close consultation with the process control engineers. No modifications should be made to a P\&ID without the authorization of the responsible process or utility engineer.

\subsection{Instrument datasheets}

Instrument datasheets on all topside system instruments are prepared on the basis of process configuration/simulation, process calculations, and P\&IDs. Process datasheets for instruments that contain only process data should be prepared so that they can be sent to specific instrument vendors. Several instrument vendors should then be considered in potential vendor lists. Finally, one vendor of a specific instrument should be selected as the contractor after technical evaluations have been performed. Detailed instrument data from the selected vendor can then be received, and instrument datasheets can be finalized. All data necessary for the procurement, installation, and operation of instruments should be represented in the instrument datasheets.

\subsection{Line size calculations}

Line size calculation is the optimized size engineering of pipes in a topside system based on the results of process configuration/simulation. It is performed after the velocity and pressure drop at operating conditions (type of fluid, flow rate, pressure, temperature) have been investigated. The line sizing should be performed according to the guidelines put forward in specific rules and regulations. A suitable line size should be selected by considering the following aspects: 
- Achieving a pressure drop compatible with the service considered (e.g., a very low ÄP is required for the main gas process line, while a higher $\Delta \mathrm{P}$ may be acceptable for the compressor discharge line).

- Seeking the most economical pipe size considering the configuration in place (e.g., for a pump discharge line, sometimes it is more economical to increase the pump head rather than increase the pipe size, which may have an impact on the supports, layout, and routing).

- Conditions that arise during a transient phase (e.g., start-up, shutdown, process upset, etc.), such as pressure surges (e.g., water hammer), vibrations, etc.

- Pipe erosion and corrosion.

- Minimum speeds to prevent deposition of suspended solids.

- Flow patterns in two-phase flow.

- Mechanical strength of the pipework.

\section{Integrated process engineering environment}

An integrated process engineering environment based on the offshore process FEED method is required for the purpose of verifying the efficiency of the FEED method. The overall scheme of the integrated environment is shown in Fig. 6. The configurations and operating procedures of the environment are as follows

(1) Process and utility configurations and simulations are performed with HYSYS (Aspentech 2009). Through these activities, the overall process and utility flows, as well as the process data (pressure, temperature, flow rate, mole fraction at each stream) are generated so the results of the FEED can be obtained. The generated outputs are then transferred to ZYQAD (Aspentech 2009),

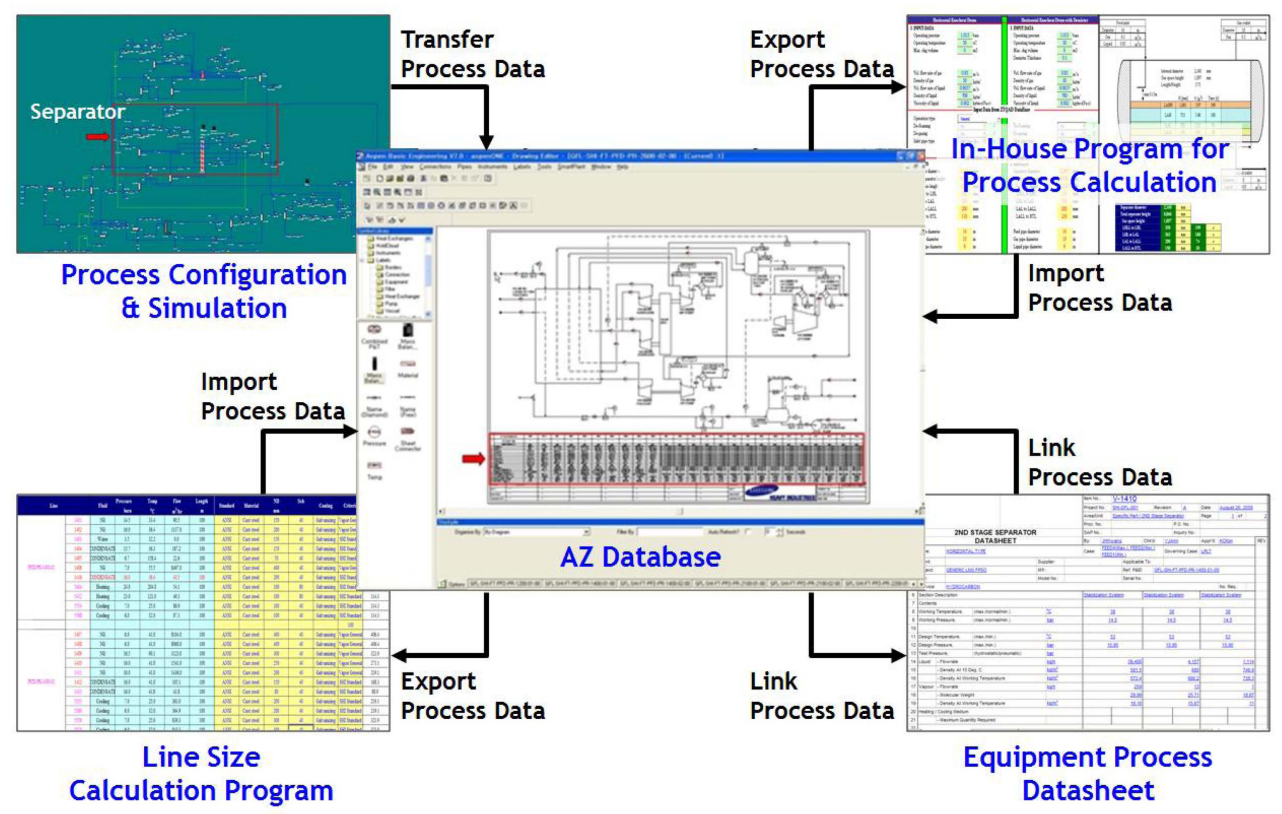

Fig. 6 Integrated process engineering environment based on the offshore FEED method 
where the process and utility flows are converted to a PFD or UFD, respectively. The other process data are stored in the ZYQAD database.

(2) Process data in the ZYQAD database are transferred to in-house programs and are used as input values to calculate the optimized specifications on equipment, piping, and instruments. The calculated specifications for the equipment, piping, and instruments in the process and utility systems are entered into the ZYQAD database.

(3) Process data in the ZYQAD database are transferred to the line size program and used as input values to calculate the pipe sizes of the overall pipe lines in the process and utility systems. The calculated pipe size values are then entered into the ZYQAD database.

(4) Process data in the ZYQAD are sent to specific equipment vendors in line with the formats of the process and utility equipment datasheets. These datasheets are then finalized after receiving detailed data (cost, weight, size, etc.) from the vendors.

(5) Process data in the ZYQAD are sent to specific instrument vendors in line with the formats of the process and utility instrument datasheets. The process and utility instrument datasheets are then finalized after receiving detailed data (cost, weight, size, etc.) from the vendors.

The integrated process engineering environment can share all processes in the ZYQAD database and perform all procedures according to the offshore process FEED method. Finally, the FEED outputs such as the weight, cost, and layout of topsides can be obtained and maintained in the integrated environment.

\section{Application to LNG FPSO topsides}

The aforementioned offshore process FEED method was applied to LNG FPSO topside systems so as to verify it effectiveness. The main areas of focus were the acquisition of the capacities on topside systems and the overall sizes of the pipes in order to obtain the costs, weights, and layout as the final process FEED results. In this paper, three stages are used to achieve the results. The first stage involves the process and utility configuration and the simulation study. The second stage consists of expanding the simulations to a PFD and UFD. The final stage involves expanding the PFD and UFD to a P\&ID.

\subsection{Process configuration and simulation study}

The results of the process configuration and simulation on LNG FPSO topside systems are shown in Fig. 7(a). The function of an LNG FPSO topside system is to separate the well stream into three components (typically called 'phases'): gas, condensate and water. These phases are then processed into marketable products or disposed of in an environmentally acceptable manner. In mechanical devices called 'separators,' gas is separated from the liquids and "free water" is separated from the condensate. These steps remove enough light hydrocarbons to produce a stable condensate with a volatility (vapor pressure) that meets sales criteria. The gas that is separated must be compressed and treated for sale. The separated gas is usually saturated with water vapor and must be dehydrated to an acceptable level. In some locations, it may be necessary to remove the heavier hydrocarbons in order to lower the hydrocarbon dew point. Contaminants such as $\mathrm{H}_{2} \mathrm{~S}$ and $\mathrm{CO}_{2}$ may be present at levels higher than those acceptable to the gas purchaser. This gas should be liquefied to LNG in order to transfer it to gas users. As such, the liquefaction process is the most important step in LNG 

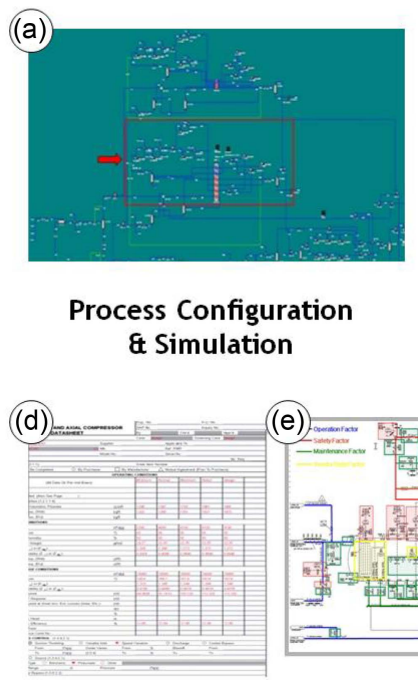

Equipment Process Datasheet
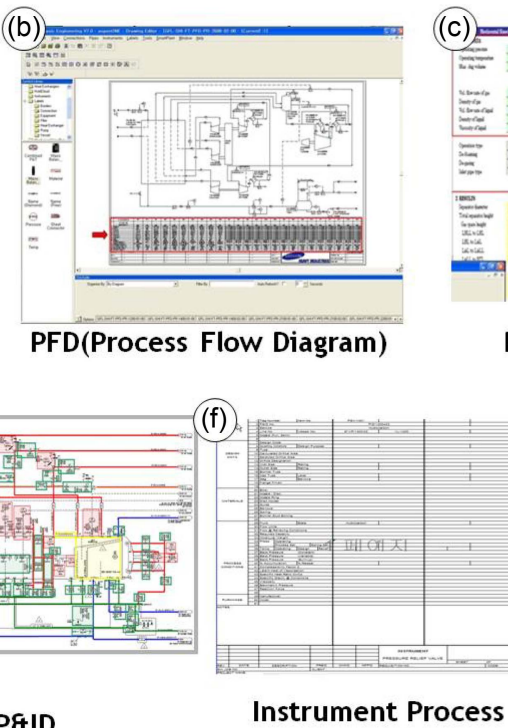

Datasheet
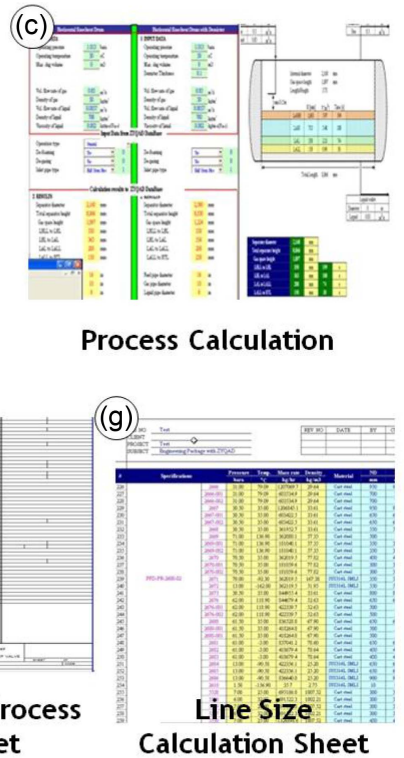

Fig. 7 Application of the offshore process FEED method to an LNG FPSO topside system

FPSO. Considering the above mentioned functions of LNG FPSO topside systems, a LNG FPSO unit consists of three processing facilities, one each for gas, condensate, and water. In this study, process configurations and simulations of these three facilities are performed in order to meet the specifications of gas for sale, condensate for sale, and water. Case studies are performed in order to determine the design cases for each system. The capacities of topside systems and the overall sizes of the pipes are then determined on the basis of the design case that satisfies the most severe condition for each system. The factors determining each design case are detailed in the following sections.

\subsubsection{Consideration of the flow rate factors}

As the volumes of gas, condensate, and water from a gas well change with time, the maximum production flow rate is used as the design case in gas-, condensate-, and water-processing systems. Therefore, case studies on the maximum gas, condensate, and water flow rates are performed in order to determine the design of each system.

\subsubsection{Consideration of the well components}

Well fluids include heavy and light components, a water component, and contaminants such as $\mathrm{H}_{2} \mathrm{~S}$ and $\mathrm{CO}_{2}$. Among these components, $\mathrm{H}_{2} \mathrm{~S}$ and $\mathrm{CO}_{2}$ have a negative influence on LNG FPSO topside systems and act as obstacles. Therefore, a sweetening system must be installed to remove these contaminants. Case studies have been conducted on each contaminant in order to determine the capacity of the sweetening system.

\subsubsection{Consideration of the pressure and temperature}

Temperature and pressure are variable in fluids from well reservoirs. Case studies have been conducted on the maximum and minimum inlet temperatures and pressures of well fluids in order to address unexpected problems. 


\subsection{Expanding the simulation to a PFD}

Shown in Fig. 7(b) is the PFD of a liquefaction system, the most important part in an LNG FPSO topsides, after the above mentioned process configuration and simulation study was completed. The PFD generated in our study is one of the most important results in the FEED stage and presents an overall oil FPSO topside system configuration with safety and control logic as well as heat and material tables.

The following are the most important factors and activities when developing a PFD from the results of a process configuration and simulation upon receipt of vendor data for equipment.

\subsubsection{Incorporation of heat and material balance}

The incorporation of the heat and material balance table, which shows physical properties such as the temperature, pressure, flow rate and mole fraction, is the most essential factor in developing a PFD from a process configuration and simulation. The capacities and pipe sizes in an LNG FPSO topside system, which consist of equipment, instruments, and pipes, are determined based on the heat and material balance in our study.

\subsubsection{Incorporation of safety and control logic}

Since the most important factor in an LNG FPSO topside system is safety, the incorporation of safety and control logic into the PFD is essential to enhance the overall understanding of the LNG FPSO topside system during operation in an offshore plant. Therefore, the safety and control logic of an LNG FPSO topside system are incorporated into the PFD in our study.

\subsubsection{Performance of the process calculation}

Shown in Fig. 7(c) is an in-house program that determines the size of the high pressure (HP) separator shown in the PFD. In-house programs developed by our team are used for the purpose of rapidly fixing the size of each system when determining the layout of the LNG FPSO topside system. In this study, the main specifications of LNG FPSO topside system equipment, such as the high pressure separator, are determined according to the heat and material balance in the PFD.

\subsubsection{Preparation of equipment datasheets}

The equipment datasheet for the HP separator is shown in Fig. 7(d). Equipment datasheets, which contain the physical properties and requirements of LNG FPSO topsides equipment, are issued to each equipment vendor. Engineering data on LNG FPSO topsides equipment can be obtained from each equipment vendor based on these equipment datasheets. The final FEED results, including the costs, weights, and sizes of topside equipment, can be obtained with these engineering data from the equipment vendor.

\subsection{Expanding a PFD to a P\&ID}

The P\&ID of the HP separator based on the PFD is shown in Fig. 7(e). As mentioned above, the costs, weights, and layout of LNG FPSO topsides equipment can be derived from the PFD. The costs, weights, and layout of LNG FPSO topsides instruments and pipes that are installed and connected to the equipment can be obtained from the P\&ID. Therefore, it is important to manage the main factors in order to develop the P\&ID from the PFD. The main factors in developing the 
P\&ID are operation, safety, and maintenance. All equipment, instruments, and pipes are installed according to the results of the study on operation, safety, and maintenance factors for each topside system. In Fig. 7(e), the pipes and instruments installed according to the results of the safety factors study are shown in red, those installed according to the results of the operation factors study are displayed in blue, those installed according to the results of the maintenance factors study are shown in green, and those installed according to the vendor data are displayed in yellow. In this study, P\&IDs on an LNG FPSO topside system are prepared by incorporating these study results into the PFD. As a result of developing P\&IDs from PFDs, the costs, weights and layout of LNG FPSO topsides instruments and pipes can be obtained. Consequently, the total costs, weights, and layouts of equipments, instruments, and pipes, which are the main components of LNG FPSO topside systems, can be obtained through the development of the P\&ID from a process configuration/simulation. That is, the final FEED results can be successfully attained through the application of the offshore process FEED method to an LNG FPSO topside system. The important factors and main steps in developing P\&IDs from PFDs and receiving vendor data on instruments and pipes are given in the following sub-sections.

\subsubsection{Consideration of operation factors}

Instruments and pipes, which are necessary for the operation of topside systems, are first installed based on the characteristics of each topside system and the PFD. In this study, necessary instruments and pipes are installed according to the results of the operation factor study.

\subsubsection{Consideration of safety factors}

Safety problems in a deep sea environment pose serious dangers to LNG FPSO topside systems. Therefore, the most important factor in developing the P\&ID is safety. Among the international rules and regulations related to safety, the American Petroleum Institute (API) code is widely used as a standard when performing a safety factor study of LNG FPSO topside systems. In this work, necessary instruments and pipes are installed based on the results of the safety factor study.

\subsubsection{Consideration of maintenance factors}

Instruments and pipes necessary for the maintenance of equipment from the PFD are installed in addition to the instruments and pipes already installed according to the results of the operation and safety factor studies. The lifetime of an LNG FPSO topside system is between 20 and 25 years. Therefore, additional instruments and pipes are installed in order to maintain LNG FPSO topside systems with minimum costs and human labor.

\subsubsection{Incorporation of vendor data}

As mentioned above, a PFD is generated based on the heat and material balance, which is the result of a process configuration and simulation. The P\&ID is then generated by the incorporation of operation, safety, and maintenance factors. Next, vendor data on the equipment, instruments, and pipes are incorporated into the P\&ID. Lastly, the sizes of pipes that connect the LNG FPSO topside system components are determined using a line size calculation and are incorporated into the P\&ID so as to finalize the P\&ID development.

\subsubsection{Preparation of instrument datasheets}

Shown in Fig. 7(f) is the instrument datasheet for the pressure safety valve (PSV), which is one of 
the instruments in the P\&IDs. Instrument datasheets, which include the physical properties and requirements of the LNG FPSO topsides instruments, are issued to each instrument vendor. Engineering data on the topsides instruments can be obtained from each instrument vendor based on these instrument datasheets. The final FEED results, including the costs, weights, and sizes of topside instruments, can be obtained using these engineering data from instrument vendors.

\subsubsection{Performance of line size calculations}

The in-house program for calculating the line sizes of LNG FPSO topside systems is shown in Fig. 7(g). Topside systems consist of various equipment suited to the characteristics of each system. Therefore, pipes are important in that they connect the equipment and occupy many portions of topside systems. In this study, the sizes of the pipes, which are shown in the P\&IDs, are calculated based on the heat and material balance shown in the PFDs.

\section{Conclusions}

The goal of the process FEED method for offshore plants is to determine the potential feasibility of well development by estimating the final process FEED results, which include the total costs, weights, and layout of offshore plants. The specifications of all equipment, instruments, and pipes, which are the main components of offshore plants, are determined to estimate the final process FEED results. In this paper, an offshore process FEED method was introduced and reviewed in order to efficiently obtain the final process FEED results. An integrated process engineering environment was then presented according to the FEED method. Finally, the offshore process FEED method was applied to LNG FPSO topsides FEED in order to investigate the benefits of our method. As a result of the application of the FEED method, the process FEED can be rapidly performed without time-consuming engineering work.

\section{Acknowledgments}

This work was supported by

(a) Industrial Strategic Technology Development Program (10035331, Simulation-based Manufacturing Technology for Ships and Offshore Plants) funded by the Ministry of Knowledge Economy (MKE, Republic of Korea)

(b) Research Institute of Marine System Engineering at Seoul National University

(c) Marine Technology Education and Research Center, through the Brain Korea 21 project of Seoul National University

(d) SM-11: "A Study on the network-based architecture of virtual system for the simulation of underwater vehicles" of the Underwater Vehicle Research Center; and

(e) National Research Foundation of Korea Grant funded by the Korean Government (KRF-2008314-D00494, KRF-2009-0086033, and R33-2008-000-10150-0)

(f) New \& Renewable Energy of the Korea Institute of Energy Technology Evaluation and Planning (KETEP) grant funded by the Korea Government Ministry of Knowledge Economy (No. 20114030200050). 


\section{References}

Barclay, M. and Yang, C.C. (2006), "Offshore LNG : The perfect starting point for the 2 phase expander", Proceedings of the Offshore Technology Conference, Houston, USA.

Barclay, M. nad Shukri, T. (2007), "Enhanced single mixed refrigerant process for stranded gas liquefaction", Proceedings of the LNG15 Conference, Barcelona, Spain.

Doris Engineering (2012), http://www.doris-engineering.com.

Hwang, J.H., Min, J.H., Ahn, Y.J., Kim, H.C., Roh, M.I. and Lee, K.Y. (2008), “Optimized methodology to build an integrated solution to offshore topside process engineering", Proceedings of the International Society of Offshore and Polar Engineers, Vancouver, Canada.

International Maritime Associates (2010). Floating production systems, Annual Report, International Maritime Associates Inc.

Jung, H.C, Lim, S.W. and Kim, Y.H. (2006), "An demand outlook of offshore oil production structures", Trans.Soc. Naval Archit.Korea (43), 49-57.

Kim, H.S., Jun, S.H., Shim, C.S., Lee, G.Y., Nam, H.S., Kang, J.K., Shin, Y.G. and Heo, J.H. (2004), "The study on local strength analysis for floater type offshore structure", Proceedings of the Annual Autumn Meeting, The Society of Naval Architects of Korea, Sancheong, Korea.

Kim, J.H., Cho, S.K., Hong, S.Y. and Kim, Y.S. (2006), "Experimental study on a dolphin- fender mooring system for pontoon-type structure", Trans.Soc. Naval Archit.Korea, 42(1), 43-49.

Lake, M., He, H., Troesch, A.W., Perlin, M. and Thiagarajan, K.P. (2000), "Hydrodynamic coefficients estimation for TLP and spar structures, J. Offshore Mech. Arct.,122(2), 118-124.

Lee, H.Y., Shin, H.K., Lim, C.G., Kim, O.H., Kang, J.M. and Yoon, M.C. (2000), "Hydroelastic responses for a very large floating structure with a breakwater", Trans.Soc. Naval Archit.Korea, 38(2), 26-32.

Lee, J.O., Lee, H.Y., Suh, Y.S. and Yoon, J.H. (1998), "Reliability of Fatigue Life Predictions for Fixed Offshore Structures", Trans.Soc. Naval Archit.Korea, 35(2), 74-82.

Matsuura, J.P. and Bernitsas, M.M. (2006), "Routes to large amplitude motions of mooring systems due to slowly varying drift", J. Offshore Mech. Arct., 128(4), 280-285.

Mustang Engineering (2012), http://www.mustangeng.com.

Na, J.H., Shim, W.S., Lee, I.H., Moon, J.S., Kim, J.W. and Shin, H.S. (2004), "FPSO quay mooring analysis in typhoon condition", Proceedings of the Annual Autumn Meeting, The Society of Naval Architects of Korea, Sancheong, Korea.

Newman, J.N. and Lee, C.H. (2002), "Boundary-element methods in offshore structure analysis, J. Offshore Mech. Arct.,124(2), 81-89.

Shin, H.K., Lee, H.Y., Lim, C.G., Shin, H.S. and Park, I.G. (2000), "Motion of a very large floating structure in irregular waves", Trans.Soc. Naval Archit.Korea, 37(4), 75-81.

Technip (2012), http://www.technip.com. 